\title{
Derivation of the bearing strength perpendicular to the grain of locally loaded timber blocks
}

\author{
T. A. C. M. van der Put
}

Published online: 18 July 2008

(C) The Author(s) 2008

\begin{abstract}
Based on the equilibrium method of plasticity, the theoretical explanation of the bearing strengths of locally loaded timber blocks is given in the Appendices. The result of the numerical construction of the slip-lines can precisely be represented by an analytical function of a logarithmic spiral that can be shown to be the exact solution. This function in one variable can be given in the power law form leading to a theoretical and experimental value of that power of 0.5 .

This power representation of the stress spreading model of the strength increase, by confined dilatation, provides simple rules for the code and a simple design method that precisely matches to the data in all circumstances and loading cases and explains the apparent contradictory test results of Suenson, the Eurocode, the French rules, Graf, Korin and Augustin et al. and, as shown before, explains other comparable loading cases as e.g. by pin dowel connections (see literature).
\end{abstract}

\section{Bestimmung der Querdruckfestigkeit von Holz bei Schwellendruck}

Zusammenfassung In den Anhängen wird auf Grundlage des Traglastverfahrens die Erklärung für die Querdruckfestigkeit von Holz bei Schwellendruck theoretisch hergeleitet. Die numerisch hergeleiteten Gleitlinien können analytisch als Funktion einer logarithmischen Spirale beschrieben werden. Es lässt sich zeigen, dass dies eine exakte Lösung darstellt. Diese Funktion mit einer Variablen

T. A. C. M. van der Put (

Faculty of Civil Engineering and Geosciences,

Timber structures and wood technology, TU Delft,

P.O. Box 5048, 2600 GA Delft, The Netherlands

e-mail: vanderp@xs4all.nl kann als Exponentialfunktion beschrieben werden, wobei sich der Exponent theoretisch und experimentell zu 0,5 ergibt.

Dieses Modell der Festigkeitssteigerung und Spannungsverteilung durch begrenzte Dilatation erlaubt eine einfache Normierung und liefert einfache Berechnungsregeln, die in allen Fällen und Belastungsarten genau mit den experimentellen Daten übereinstimmen, und die scheinbar widersprüchlichen Versuchsergebnisse von Suenson, des Eurocodes, der französischen Regeln, von Graf, Korin und Augustin et al. sowie andere vergleichbare Belastungsarten, wie zum Beispiel bei Stabdübelverbindungen (siehe Literatur), erklären.

\section{Introduction}

Because of the revived attention to the bearing strength of timber beams and the proposal of design rules for the Eurocode 5 , it is necessary to regard the theoretical explanation of the bearing strength of supports as the right basis of design only. This theory of the strength of locally loaded blocks completed here was developed by the author long ago and has been applied in many reports of the Stevin Laboratory like e.g. in van der Put (1988), where it was shown to be the only possible theory to explain the very high embedding strength of particle boards in compression and the very high embedding strength of nailed particle boards to wood connections. The theory is also discussed in CIB-papers, e.g. in van der Put (1988) and van der Put (1991), and in an internal report for the CIB-Stability Committee and more recently in van der Put and Leijten (2000), where it was shown to fully and precisely explain the data of Ballerini (1999) and the Karlsruhe data of joints with one and two dowels (van der Put and Leijten 2000). 
The theoretical derivations in the Appendices result in Eq. 1 which provide a simple design rule being able to explain all mutual strongly different empirical results, as discussed in the following. It can be seen that the measurements are close to the low flow strain prediction of the theory with a spreading slope of $45^{\circ}$, giving a very good explanation of the data with different configurations.

The given design rules for bearing blocks do not apply for support stresses in continuous beams because the shear strength is also a determining factor. For the combined stresses in the beam, the failure criterion of van der Put (1982) has to be applied as is shown in van der Put (2006a). This will be discussed in a following article.

\section{Bearing strength perpendicular to the grain of locally loaded blocks}

The local compression strength perpendicular to the grain may increase due to confined dilatation perpendicular to the loading direction. This is explained in Appendix A by the equilibrium method of the theory of plasticity. As derived, the increase of strength is proportional to $\sqrt{L / s}$ according to Eq. 1:

$f_{c, s}=c f_{c, 90} \sqrt{L / s} \approx f_{c, 90} \sqrt{L / s}$.

The definition of $L$ and $s$ is given in Figs. 5-7. The strength values $f_{c, s}$ are the top-values of the measured curves of Fig. 1. The cube strength $f_{c, 90}$ at the top of curve "a" at $15 \%$ strain is here $3.6 \mathrm{MPa}$. The measured maximal strength values, given in Table 1 , are precisely according to the theory.

Figure 1 shows the strength increase with increasing possibility of spreading of the load. It further shows that there is a maximal spreading of about $4 H$ because the strength of specimen "e" with $L=5 s=5 H$ is as strong as specimen "d" with $L=4 s=4 H$. The definition of $L, s$ and $H$ is given in Figs. 5-7. Thus, the maximal spreading-length is $4 H$, or better: $3 H+s$. Because $s=H$, the spreading is $3 H$, thus 2 times $1.5 H$ of both sides. Thus, $L=2 \cdot 1.5 H+$ $s=3 H+H=4 H$. The spreading is $1.5: 1$, as is applied in Fig. 6 . The same maximal value of the spreading slope of $1.5: 1$ also follows from other investigations like e.g. of the French design rules (see Table 2) where for higher values

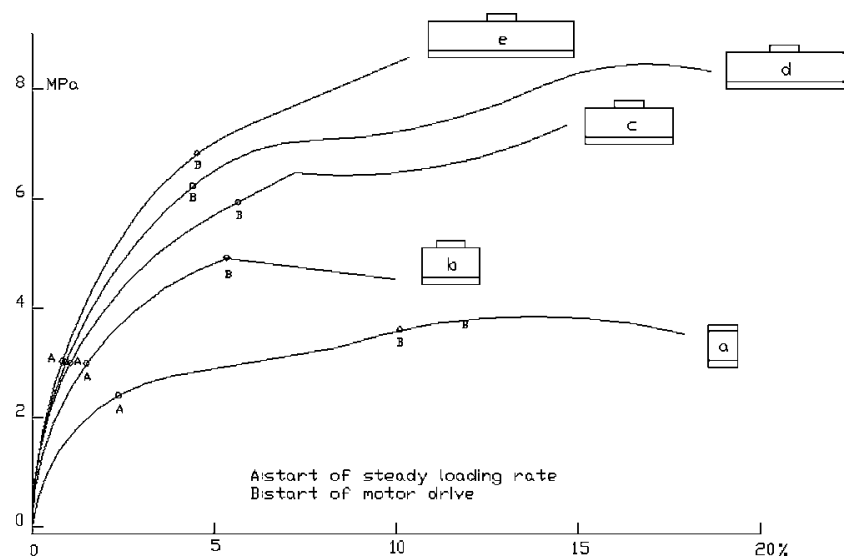

Fig. 1 Bearing strength $f_{c, s}$ perpendicular to the grain. Specimen 150 $\times 150 \mathrm{~mm}^{2}$, lengths: $L=150,300,450,600,750 \mathrm{~mm}$, of curves a to e with $s=150 \mathrm{~mm}$, according to the data of Suenson in Kollmann (1984)

Abb. 1 Querdruckfestigkeit $f_{c, s}$, Probenquerschnitt $150 \times 150 \mathrm{~mm}^{2}$, Probenlänge $L=150,300,450,600,750 \mathrm{~mm}$; mit jeweils $s=$ 150 mm, gemäß den Daten von Suenson in Kollmann (1984)

of "a", above $a / H \geq 1.5$, there is also no strength increase. When the ultimate state is chosen at a small plastic deformation, as is often done, the spreading slope is close to $1: 1$ of the elastic state. This is also to be expected when there is no friction at the bearing plates or when the height $H$ is not limiting but the spreading length $L$ is limiting being equal then to the length of the block. On this determining case for practice the derivation of Eq. A.17 from Eq. A.13 is based on Appendix A.

The rule of the Eurocode, given in Larsen (1975), Eq. (4.20), follows from Eq. 1 after scaling to a maximal value $s_{0}$. Because $f_{c, s}=f_{c, 90} \sqrt{L / s}$ and $f_{c, s, 0}=f_{c, 90} \sqrt{L / s_{0}}$ it follows:

$f_{c, s} / f_{c, s, 0}=\sqrt{s_{0} / s}=\left(s_{0} / s\right)^{0.5}$,

with $s \leq s_{0}=100 \mathrm{~mm}$. In Larsen (1975), the exponent 0.5 is replaced by 0.4 , indicating that a lower ultimate strain is chosen as ultimate state. This also is the case for the safe code rules of Canada, Denmark, Norway, Sweden and the UK. For small values of $s$ (e.g. for pin-dowels) the Weibull volume effect is noticeable and the value of the draft CIB timber code with a power of 0.25 indicates this effect and the kink in the loading line (by splitting along the grain)
Table 1 Bearing strengths perpendicular to the grain of locally loaded blocks

Tabelle 1 Querdruckfestigkeit bei Schwellendruck

\begin{tabular}{lcccccc}
\hline Curve & $L / s$ & $\sqrt{L / s}$ & $\begin{array}{c}f_{c, 90} \\
(\mathrm{MPa})\end{array}$ & $\begin{array}{c}\text { Theory } \\
f_{c, s}=1.1 f_{c, 90} \sqrt{L / s} \\
(\mathrm{MPa})\end{array}$ & $\begin{array}{c}\text { Measurements } \\
f_{c, s} \\
(\mathrm{MPa})\end{array}$ & $\begin{array}{c}\text { Ultimate } \\
\text { strain }\end{array}$ \\
\hline $\mathrm{a}$ & 1 & 1 & 3.63 & $1.1 f_{c, 90}=4.0$ & & $15 \%$ \\
$\mathrm{~b}$ & 2 & $\sqrt{2}$ & & 5.6 & 5.5 & $5.5 \%$ \\
$\mathrm{c}$ & 3 & $\sqrt{3}$ & & 6.9 & 6.95 & $13 \%$ \\
$\mathrm{~d}$ & 4 & $\sqrt{4}$ & & 8.0 & 8.0 & $15 \%$ \\
$\mathrm{e}$ & 5 & $\sqrt{5}$ & limit & $\approx$ as curve “d" & 8.3 & $10 \%$ \\
\hline
\end{tabular}


Table 2 Values of

$k_{c}=f_{c, s} / f_{c, 90}$

Tabelle 2 Werte für

$k_{c}=f_{c, s} / f_{c, 90}$

\begin{tabular}{lllll}
\hline$s / H$ & \multicolumn{4}{c}{$a / H$} \\
& $\geq 1.5$ & 1 & 0.5 & 0 \\
\hline 1 & 2 & 1.5 & 1.25 & 1 \\
2 & 1.5 & 1.25 & 1.12 & 1 \\
$\geq 3$ & 1 & 1 & 1 & 1 \\
\hline
\end{tabular}

was chosen as ultimate state. However, because $L$ and hence $H$ are eliminated in the derivation of Eq. 2, the equation is not generally applicable. For very small values of $H$ for instance, there is no spreading at all and the equation doesn't apply. Furthermore $f_{c, s, 0}$ is wrongly taken to be equal to $f_{c, 90}$ for $s=s_{0}=150 \mathrm{~mm}$. Therefore, the right rule, based on the theoretical Eq. 1, was proposed for the timber code in the past, e.g. in van der Put (1991) and van der Put and Leijten (2000).

The French rules, given in Table 2 and mentioned in Larsen (1975), correctly show the dependence of the strength on $H$. The Table shows the boundary value of $a / H=1.5$, mentioned above. When $a / H=(L-s) / 2 H \geq$ 1.5, thus when $L \geq 3 H+s$, the maximal spreading is reached according to Fig. 1. Another boundary of Table 2 is given for $s / H \geq 3$.

It then is assumed, that in the middle of the specimen the same conditions as in the cube test appear (see Fig. 3). This applies for fully flexible, frictionless bearing plates. The same condition in Table 2 is assumed to apply for $a=0$ in Fig. 2.

Without friction, spreading is not possible at the edge and the strength is equal to the strength of the cube test. With friction along the plates, the confined pressure may e.g. be build up, even for $s=L$, according to Fig. 4 .

The influence of no friction along the bearing plate in the strong direction (and thus full friction in the width direction) can be assessed as lower boundary by assuming that only symmetrical spreading is possible. This is given in Table 3 where: $L=2 a+s$. According to Eq. 1 it then is: $k_{c}=\sqrt{L / s}=\sqrt{1+(2 a / H) /(s / H)}$ in Table 3 .
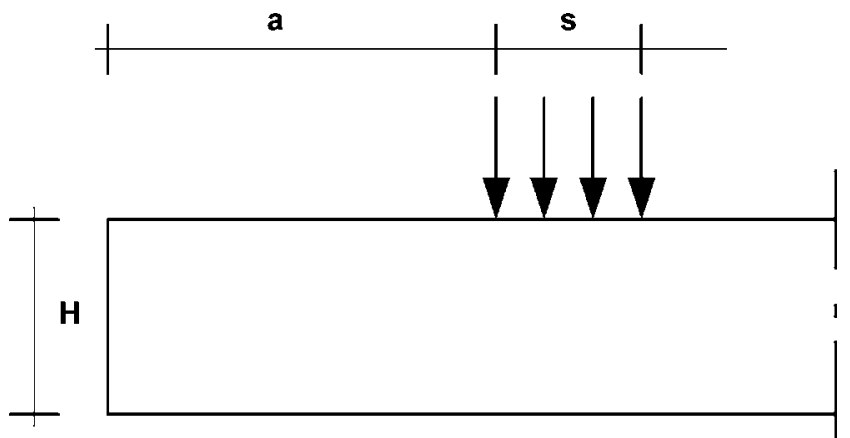

Fig. 2 Locally loaded block

Abb. 2 Probe mit Schwellendruck

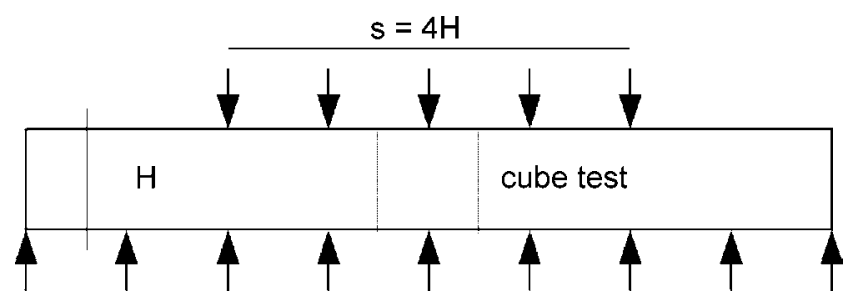

Fig. 3 Cube test condition in the middle when there is no friction Abb. 3 Würfel in der Mitte bei fehlender Reibung

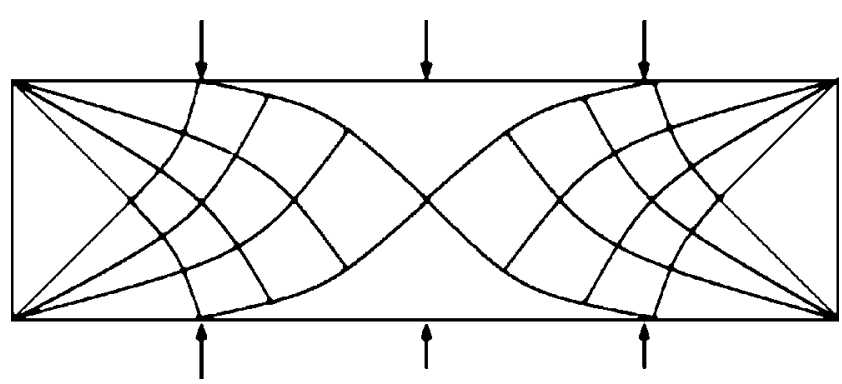

Fig. 4 Slip lines of failure between two plates by friction along the plates

Abb. 4 Bruchgleitlinien zwischen zwei Platten bei Reibung entlang der Platten

These values are close to the values of Table 2 of the French rules and are comparable when a reduction factor is applied in Table 3 according to:

$0.9\left(\begin{array}{ll}1.7 & 1.4 \\ 1.4 & 1.2\end{array}\right)=\left(\begin{array}{ll}1.5 & 1.25 \\ 1.25 & 1.1\end{array}\right)$.

Thus, when disregarding the limit $c=1$ in the first column, $c=0.9$ in columns 2 and 3 is used, the safe lower boundaries according to the French rules are indicated.

In Korin (1990), the test results are given according to Fig. 5 , in the range where not $H$, but $L$ is limiting for spreading because: $L<2 H+s$ for the central loaded specimen.

The determination of $f_{c, 90}$ is done on the same specimen, thus on the specimen of Fig. 5 with an upper loading plate of length $L$, the same length as the bottom plate, giving by this form a higher strength than follows from the common standard compression test. The ultimate strain was chosen to be $2.5 \%$. This compression strength was compared with the strength of the ASTM-bearing test, being the same test as given by the central loaded specimen of Fig. 5, however with a length of the upper plate of $s=L / 3$. This explains why the

Table $3 k_{c}=f_{c, s} / f_{c, 90}$ by symmetry

Tabelle 3 Werte für $k_{c}=f_{c, s} / f_{c, 90}$

\begin{tabular}{lllll}
\hline$s / H$ & \multicolumn{4}{c}{$a / H=(L-s) / 2 H$} \\
& $\geq 1.5$ & 1 & 0.5 & 0 \\
\hline 1 & 2 & 1.7 & 1.4 & 1 \\
2 & 1.6 & 1.4 & 1.2 & 1 \\
$\geq 3$ & 1 & 1 & 1 & 1 \\
\hline
\end{tabular}


Fig. 5 Spreading $1: 1$ in a central loaded block and end-loaded block

Abb. 5 Lastausbreitung in einer mittig und einer am Rand belasteten Probe

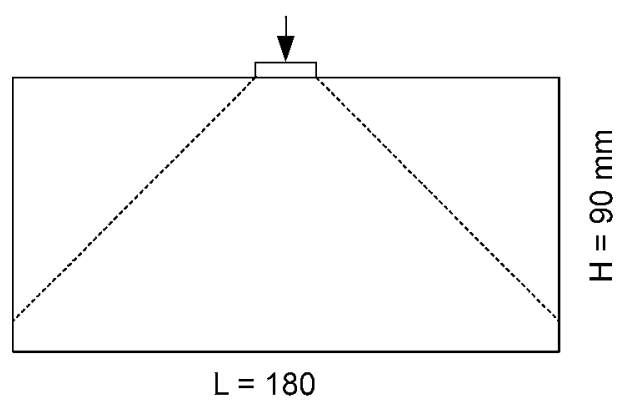

ASTM values of Korin (1990) are $\sqrt{L / s}=\sqrt{3}$ times higher than according to the strength of the same specimen with $s=L$.

In Table 4, the test results (of a series of three specimens) are compared with Eq. 1 and it is seen that also non-symmetrical spreading of end loaded blocks is possible because of the friction between plate and specimen.

According to the Eurocode a limiting value occurs at $s / L \leq 0.125$. In this case, it be due to a local mechanism. The results here however don't show such an empirical reduction of the strength with respect to the theoretical value. The theoretical limit values due to local mechanisms also show much higher values of $k_{c}$. In Table 5, the empirical value of $c$ of Eq. 1 is given based on the tests in Korin (1990).

In Fig. 6, the results of tests on two sided locally loaded long blocks are given.
From the Figure it follows that: $s+3 \rho H=L+3 .(1-$ $\rho) H$. Thus:

$\rho=0.5+\frac{L-s}{6 H}$

and thus the equivalent spreading factor (of the strength determining plate) is:

$\frac{L^{\prime}}{s}=\frac{s+3 \rho H}{s}=1+\frac{3 H}{s}\left(0.5+\frac{L-s}{6 H}\right)=0.5+\frac{3 H+L}{2 s}$,

with $H=179 \mathrm{~mm} ; L=350 \mathrm{~mm}$ and $b=181 \mathrm{~mm}$ according to the measurements of Graf it follows:

$k_{c, 90}=c \sqrt{\frac{L^{\prime}}{s}}=1.1 \sqrt{0.5+\frac{3 H+L}{2 s}}$

or:

$k_{c, 90}=1.1 \sqrt{0.5+(3 \cdot 178+350) / 2 s}=1.1 \sqrt{0.5+442 / s}$
Table 4 Values of $k_{c}$ according to the test-specimens of Fig. 5 Tabelle 4 Werte für $k_{c}$ gemäß den Prüfkörpern in Abb. 5

\begin{tabular}{|c|c|c|c|c|}
\hline \multirow[b]{2}{*}{$s / L$} & \multicolumn{2}{|c|}{ Measurements } & \multicolumn{2}{|c|}{ Theory } \\
\hline & $\begin{array}{c}\text { Central loaded } \\
k_{c}\end{array}$ & $\begin{array}{l}\text { End loaded } \\
\qquad k_{c}\end{array}$ & $\begin{array}{r}\text { Central loaded } \\
\text { Eq. }\end{array}$ & $k_{c}=\sqrt{L / s}$ \\
\hline$\overline{1}$ & 1 & 1 & 1 & 1 \\
\hline 0.875 & 1.063 & 1.063 & $\sqrt{1 / 0.875}=1.07$ & $\sqrt{1 / 0.875}=1.07$ \\
\hline 0.75 & 1.188 & 1.156 & $\sqrt{1 / 0.75}=1.16$ & $\sqrt{1 / 0.75}=1.16$ \\
\hline 0.625 & 1.375 & 1.281 & $\sqrt{1 / 0.625}=1.27$ & $\sqrt{1 / 0.625}=1.27$ \\
\hline 0.5 & 1.625 & 1.438 & $\sqrt{1 / 0.5}=1.41$ & $\sqrt{(0.5+0.5) / 0.5}=1.41$ \\
\hline 0.375 & 1.969 & 1.625 & $\sqrt{1 / 0.375}=1.63$ & $\sqrt{(0.375+0.5) / 0.375}=1.53$ \\
\hline 0.25 & 2.344 & 1.875 & $\sqrt{1 / 0.25}=2$ & $\sqrt{(0.5+0.25) / 0.25}=1.73$ \\
\hline 0.125 & 2.781 & 2.156 & $\sqrt{L / 0.125 L}=2.8$ & $\sqrt{(0.5+0.125) / 0.125}=2.2$ \\
\hline
\end{tabular}

\begin{tabular}{|c|c|c|c|c|c|c|}
\hline \multirow{3}{*}{$s / L$} & \multicolumn{2}{|c|}{ Measurements } & \multicolumn{2}{|c|}{ Theory $k_{c}=\sqrt{L / s}$} & & \\
\hline & \multirow{2}{*}{$\begin{array}{c}\text { Central } \\
\text { loaded } \\
k_{c} \\
\end{array}$} & \multirow{2}{*}{$\begin{array}{c}\text { End } \\
\text { loaded } \\
k_{c}\end{array}$} & \multirow{2}{*}{$\begin{array}{c}\text { Central } \\
\text { loaded } \\
k_{c}\end{array}$} & \multirow{2}{*}{$\begin{array}{c}\text { End } \\
\text { loaded } \\
k_{c} \\
\end{array}$} & \multicolumn{2}{|c|}{$c$-values of Eq. 1} \\
\hline & & & & & $c=k_{c} / \sqrt{L / s}$ & $=k_{c} / \sqrt{L / s}$ \\
\hline 1 & 1 & 1 & 1 & 1 & 1 & 1 \\
\hline 0.785 & 1.063 & 1.063 & 1.07 & 1.07 & 1 & 1 \\
\hline 0.75 & 1.188 & 1.156 & 1.16 & 1.16 & 1.03 & 1 \\
\hline 0.625 & 1.375 & 1.281 & 1.27 & 1.27 & 1.09 & 1 \\
\hline 0.5 & 1.625 & 1.438 & 1.41 & 1.41 & 1.15 & 1 \\
\hline 0.375 & 1.969 & 1.625 & 1.63 & 1.53 & 1.2 & 1.06 \\
\hline 0.25 & 2.344 & 1.875 & 2.0 & 1.73 & 1.17 & 1.08 \\
\hline 0.125 & 2.781 & 2.156 & 2.8 & 2.2 & 1 & 1 limit \\
\hline mean of $\mathrm{c}$ & & & & & 1.08 & 1 \\
\hline
\end{tabular}

Table 5 Values of $f_{c, s} / f_{c, 90}=k_{c}$ and of $c=k_{c} / \sqrt{L / s}$, according to Table 4

Tabelle 5 Werte für

$f_{c, s} / f_{c, 90}=k_{c}$ und $c=k_{c} / \sqrt{L / s}$ gemäß Tabelle 4 


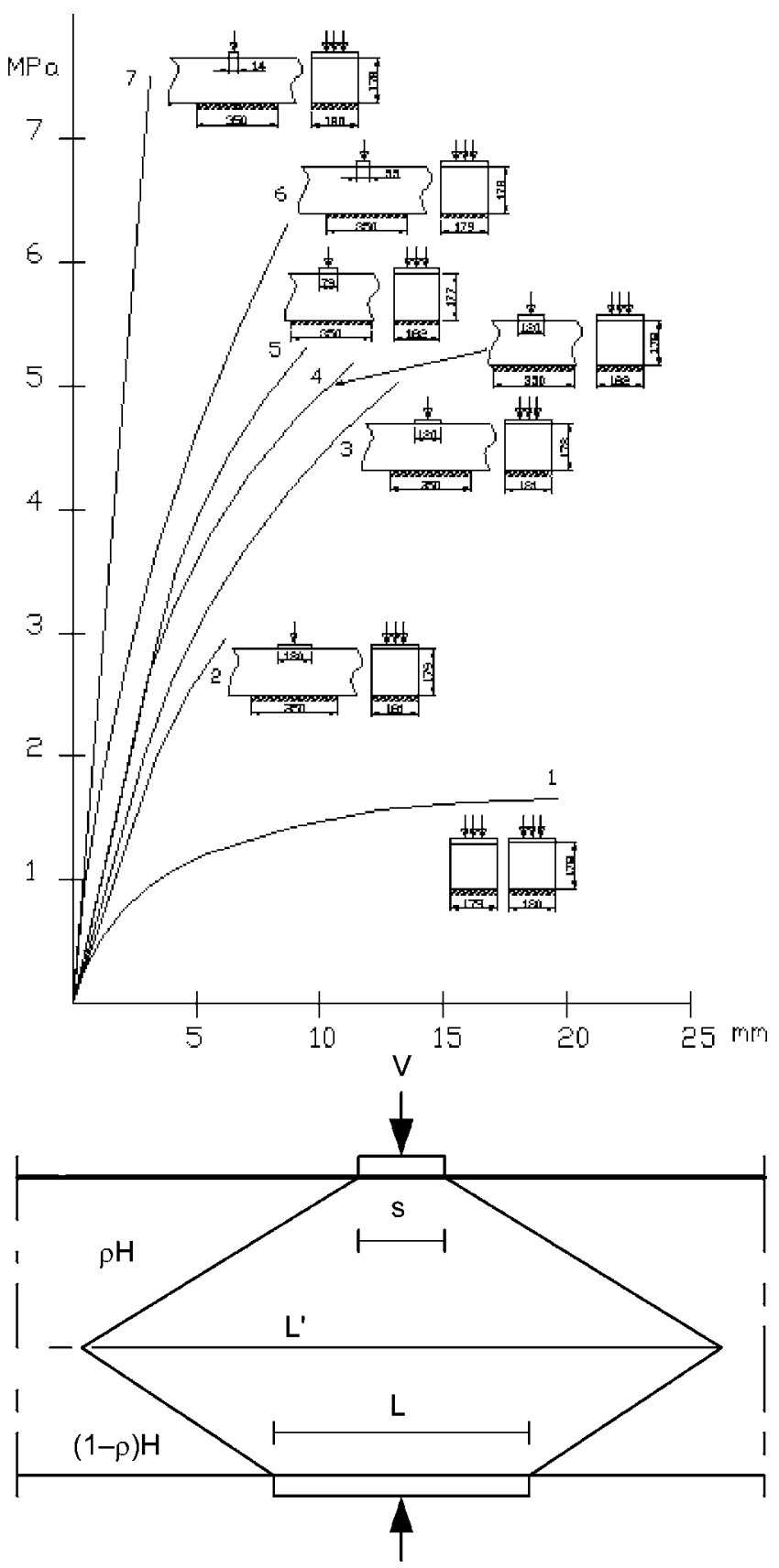

Fig. 6 Local loading perpendicular to the grain by Graf in Kollmann (1984) with assumed spreading

Abb. 6 Querdruckversuche von Graf in Kollmann (1984)

leading to the values of $f_{s}$ at $5 \mathrm{~mm}$ deformation (see Fig. 6) of the curves: $1: 1.6-2: 3.0-3: 3.6-5: 4.3-$ $6: 5.2 \mathrm{MPa}$, about the same as the measurements as can be seen in Table 6. For long blocks with respect to the bearing plates the maximal spreading will occur at both plates according to Fig. 6 of Graf inKollmann (1984).

The highest maximum is not shown (line 7 of Fig. 6). Predicted according to the last formula it follows $f_{s}=10 \mathrm{MPa}$. However, this may be cut off by a local mechanism. Because $f_{c, s} \geq 7.5 \mathrm{MPa}$ is measured, the maximum value of $k_{c, 90}$ is at least $7.5 / 1.6=4.7$, near the theoretical value obtained from a local failure mechanism giving a value of 6 .

The measurements of Fig. 6 show a constant loading rate test with a sudden stress redistribution by instability at the end of the test. Therefore, the curves 2, 5 and 6 ended at $6 \mathrm{~mm}$ or $3.4 \%$ strain, so that all the strength was defined at this strain.

Next, the theoretical explanation of the data in Augustin et al. (2006) is discussed. According to the theory Eq. 1, the compression strength perpendicular to the grain of a locally loaded bearing block increases with a factor $k_{c}$ according to:

$k_{c}=f_{c, s} / f_{c, 90}=\sqrt{L / s}$.

Because the $1 \%$ permanent strain $(<3 \%$ total strain) is chosen as ultimate strain, the stress distribution will be close to the elastic one and a spreading of about 1 to 1 or $45^{\circ}$ (see Appendix A), can be assumed in Fig. 7. The maximal spreading at higher strains will be 1.5 to 1 . Thus, the length $L$ will be in case 1 of Fig. $1, L=200 \alpha+150$. In case 2 it is: $L=200 \alpha+150+100$, and in case $3: L=2 \alpha 200+$ $150 \mathrm{~mm}$, where $\alpha=1$ to 1.5 . The length $s=150 \mathrm{~mm}$. For a specimen height of $480 \mathrm{~mm}$, all values of 200 in the expressions of $L$ should be replaced by 480 .

Thus: case $1: k_{c}=\sqrt{L / s}=\sqrt{(200+150) / 150}=1.53$ to $\sqrt{(1.5 \cdot 200+150) / 150}=1.73$, etc.

In case 3 with $H=480, L$ can not be higher than the length of the specimen of $980 \mathrm{~mm}$ and thus this length is the real spreading length giving $k_{c}=\sqrt{980 / 150}=2.56$.

It can be seen in Table 7 that the measurements are close to the applied low strain prediction of the theory with a spreading slope of $45^{\circ}$ (see Appendix A), giving a good explanation of the data at the different configurations. The

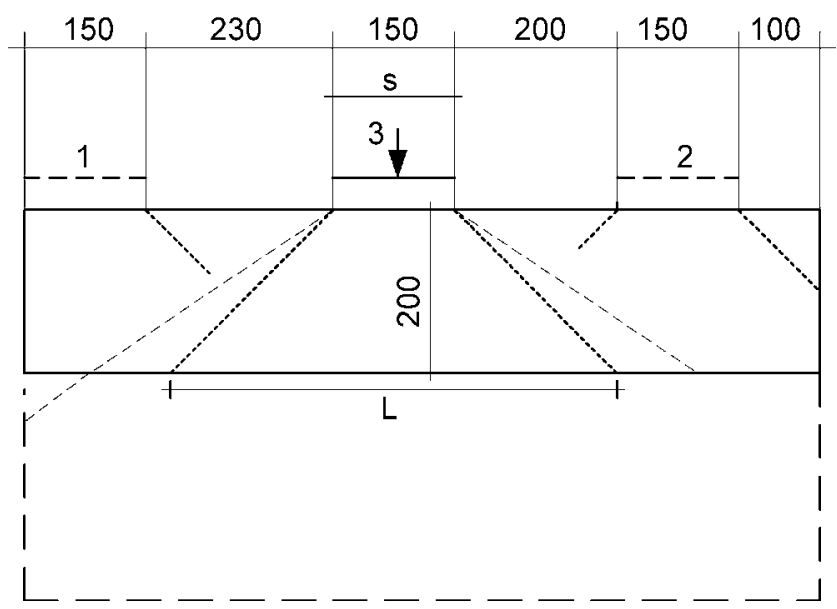

Fig. 7 Test specimen in Augustin et al. (2006)

Abb. 7 Probe gemäß Augustin et al. (2006) 
Table $6 k_{c, 90}=f_{c, s} / f_{c, 90}=$ $1.1 \sqrt{0.5+44.2 / s}$

Tabelle $6 k_{c, 90}=f_{c, s} / f_{c, 90}=$ $1.1 \sqrt{0.5+44.2 / s}$

\begin{tabular}{lcccccc}
\hline Curve & $\begin{array}{c}s \\
(\mathrm{~cm})\end{array}$ & $\begin{array}{c}f_{c, 90} \\
(\mathrm{MPa})\end{array}$ & $k_{c, 90}$ & $\begin{array}{c}\text { Theory } \\
f_{c, s} \\
(\mathrm{MPa})\end{array}$ & $\begin{array}{c}\text { Measurements } \\
f_{c, s} \\
(\mathrm{MPa})\end{array}$ & $\begin{array}{c}\text { Ultimate } \\
\text { strain } \\
6 / 178 \text { or: } \\
3.4 \%\end{array}$ \\
\hline 1 & 18 & 1.6 & & 1.6 & 1.6 & $3.4 \%$ \\
2 & 18 & & 1.89 & 3.0 & 3.0 & $3.4 \%$ \\
3 & 12 & & 2.25 & 3.6 & 3.3 & $3.4 \%$ \\
5 & 7.9 & & 2.72 & 4.3 & 4.3 & $3.4 \%$ \\
6 & 5.5 & & 3.21 & 5.2 & 5.4 & $>1 \%$ \\
7 & 1.4 & & 6.23 & 10 or local limit & $>7.5$ & \\
\hline
\end{tabular}

Table 7 Empirical verification of the theoretical values of $k_{c}$ Tabelle 7 Empirischer Nachweis der theoretischen Werte für $k_{c}$

\begin{tabular}{lrrr}
\hline$k_{c}=\sqrt{L / s}$ & $\begin{array}{c}\text { Theory, } \\
\text { 1\% strain } \\
\alpha=1\end{array}$ & $\begin{array}{c}\text { Measurements } \\
1 \% \text { strain }\end{array}$ & $\begin{array}{c}\text { Theory, prediction } \\
\text { for high strain } \\
\alpha=1.5\end{array}$ \\
\hline$h=200 \mathrm{~mm}$ & & & $k_{c}=1.73$ \\
case 1 & $k_{c}=1.53$ & $=1.58$ & $=2.24$ \\
case 2 & $=1.73$ & $=1.94$ & $=2.24$ \\
case 3 & $=1.91$ & & $k_{c}=2.41$ \\
$h=480 \mathrm{~mm}$ & & $k_{c}=1.82$ & $=2.54$ \\
case 1 & $k_{c}=2.05$ & $=2.12$ & $=2.56$ \\
case 2 & $=2.21$ & $=2.46$ & \\
case 3 & $=2.56$ & &
\end{tabular}

higher strain predictions of the theory are in fact verified by the measurements of Fig. 1.

The discussion of the Weibull volume effect of the bearing or embedding strength $f_{c, s}$ of e.g. pin-dowels can be found in van der Put (1988) and van der Put and Leijten (2000). This effect should be regarded separately. The measured value of the power of 0.66 for embedding strength of pins in particle board consists of 0.5 due to the spreading effect, plus 0.16 of the volume effect (van der Put 1988).

\section{Conclusion}

It can be concluded that the theory gives an excellent explanation and precise fit of all the apparent contradictory test results of Suenson in Kollmann (1984), the Eurocode and the French rules in Larsen (1975), Graf in Kollmann (1984), Korin (1990) and Augustin et al. (2006) in all circumstances and loading cases.

Therefore, the proposal of the past (van der Put 1991, van der Put and Leijten 2000) remains to use the right design rules for the codes, based on the theory as necessary, leading to the following rules for bearing blocks for the Eurocode:

$\sigma_{c, 90, d} \leq k_{c, 90} f_{c, 90, d}$,

where:

$k_{c, 90}=\sqrt{L / s} \quad$ with: $\quad L \leq a+s+l_{1} / 2 ; L \leq 3 H+s$ and: for safe rules (when friction is only in the width direction), the conditions are:

$L \leq 2 a+s ; L \leq s+l_{1} ; L \leq 2 H+s$,

$l_{1}$ is the intermediate distance between two local loads, (like in the code proposal).

For the bearing strength of a middle section of a beam between two plates of lengths $L$ and $s$, it is

$k_{c, 90}=1.1 \sqrt{0.5+\frac{3 H+L}{2 s}} \leq 5$.

\section{Appendix}

\section{A Derivation of the bearing strength perpendicular to the grain of locally loaded blocks and of the spreading equation by the method of characteristics}

The dependence of the strength upon spreading can be explained by the equilibrium method of the theory of plasticity. In the plastic region, a stress field can be constructed in the specimen that satisfies the equilibrium conditions:

$\frac{\partial \sigma_{x}}{\partial x}+\frac{\partial \tau}{\partial y}=0 \quad$ and $\quad \frac{\partial \tau}{\partial x}+\frac{\partial \sigma_{y}}{\partial y}=0$

and the boundary conditions and surmounts the failure criterion Eq. A. 2 nowhere.

In Eq. A.1, $\sigma_{x}$ and $\sigma_{y}$ are the normal stresses in $x$ - and $y$ directions and $\tau$ is the shear stress. As failure criterion, an 
inscribed Tresca criterion within the von Mises criterion of the isotropic matrix, Eq. A.2 can safely be used

$\left(\sigma_{1}-\sigma_{2}\right) / 2=k=f_{v}$,

where $\sigma_{1}$ and $\sigma_{2}$ are the principal stresses.

This failure criterion applies after a flow and hardening stage in the weak directions until quasi isotropic flow behaviour occurs (of the matrix) followed by further hardening and flow (van der Put 1982). In Fig. 8, the Mohr-circle of the failure condition is given with the general stress state $\sigma_{x}, \sigma_{y}, \tau$. In Fig. 8 it is:

$p=\left(\sigma_{1}+\sigma_{2}\right) / 2$ and $k=\left(\sigma_{1}-\sigma_{2}\right) / 2$.

In general it is: $\quad p=\sigma_{y}+k \cos 2 \psi=\sigma_{x}-k \cos 2 \psi$

and $\tau=k \sin 2 \psi$,

where $\psi$ is the slope of the plane of $\sigma_{2}$. Substitution of these equations of $\sigma_{x}, \sigma_{y}, \tau$ in the equilibrium equations gives

$$
\begin{aligned}
& \frac{\partial p}{\partial x}-2 k \sin 2 \psi \frac{\partial \psi}{\partial x}+2 k \cos 2 \psi \frac{\partial \psi}{\partial y}=0 \\
& \frac{\partial p}{\partial y}+2 k \cos 2 \psi \frac{\partial \psi}{\partial x}+2 k \sin 2 \psi \frac{\partial \psi}{\partial y}=0 .
\end{aligned}
$$

Multiplication of Eq. A.5 by $\tan (\psi-\pi / 4)$ and then addition with Eq. A.4 gives:

$\frac{\partial a}{\partial x}+\tan (\psi-\pi / 4) \frac{\partial a}{\partial y}=0$,

where $\mathrm{a}=p-2 k \psi$. Thus, along the line (the characteristic) with slope

$\mathrm{d} y / \mathrm{d} x=\tan (\psi-\pi / 4), \quad$ it is $\quad a=$ constant.

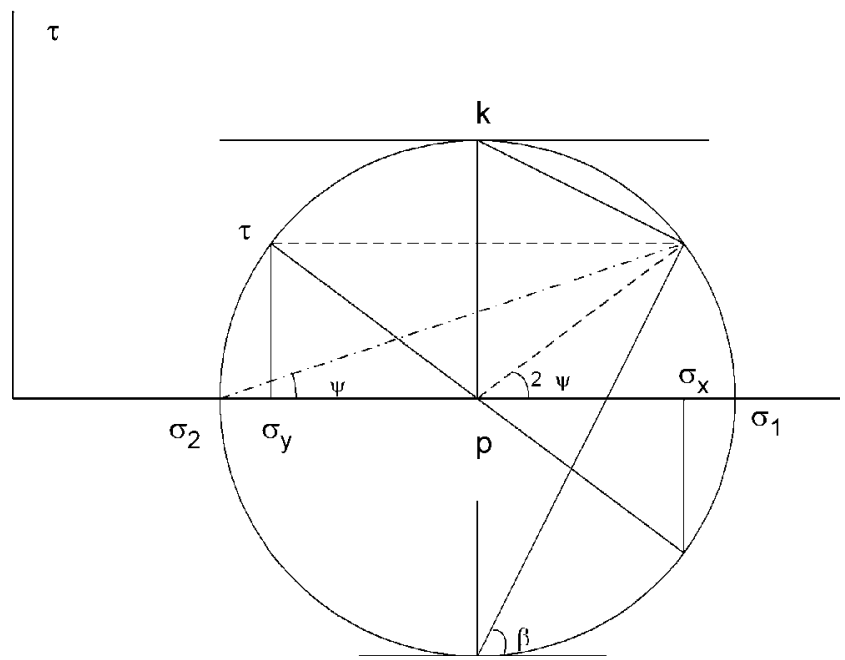

Fig. 8 Tresca failure condition

Abb. 8 Bruchkriterium nach Tresca
The same can be done by multiplication of $\tan (\psi+\pi / 4)$, leading to

$\frac{\partial b}{\partial x}+\tan (\psi+\pi / 4) \frac{\partial b}{\partial y}=0$

giving $b=p+2 k \psi=$ constant along the characteristic with $\mathrm{d} y / \mathrm{d} x=\tan (\psi+\pi / 4)$.

In van der Put (2006b) it is shown that these lines are real characteristics and the slopes of both orthogonal characteristics thus are:

$\frac{\mathrm{d} y}{\mathrm{~d} x}=\tan \left(\psi+\frac{\pi}{4}\right) \quad$ and $\quad \frac{\mathrm{d} y}{\mathrm{~d} x}=\tan \left(\psi-\frac{\pi}{4}\right)$,

while along the first the second characteristic applies, respectively:

$p-2 k \psi=a=\mathrm{constant}$

$p+2 k \psi=b=$ constant .

Calculation of the network of these slip-lines is done numerically. This is discussed in van der Put (2006b). In Fig. 9, $\theta$ increases with the increase of $H$ and as a result of the numerical construction of the slip-lines, discussed by Schwartz (1969), this increase appeared to follow precisely the empirical analytical function:

$\theta \approx 0.62 \ln (2 H / s)$

This can be explained as follows. At the end of the outer curved slip-line, over a length $R \mathrm{~d} \phi$, according to the ropeequation $N \mathrm{~d} \phi=\sigma R \mathrm{~d} \phi$ or $N=\sigma R$, where $N$ is the normal force along the slip-line. Further $\mathrm{d} N=\tau R \mathrm{~d} \phi$, or $\sigma \mathrm{d} R=$ $\tau R \mathrm{~d} \phi$, or $\mathrm{d}(\ln R) / \mathrm{d} \phi=\tau / \sigma=c$ and thus $R=R_{0} \exp (c \phi)$, what is a logarithmic spiral. Now it follows:

$\frac{R_{L}}{R_{s}}=\frac{H}{s / 2}=\exp \left(c\left(\theta_{L}-\theta_{s}\right)\right)=\exp \left(1.61 \theta_{t}\right)$
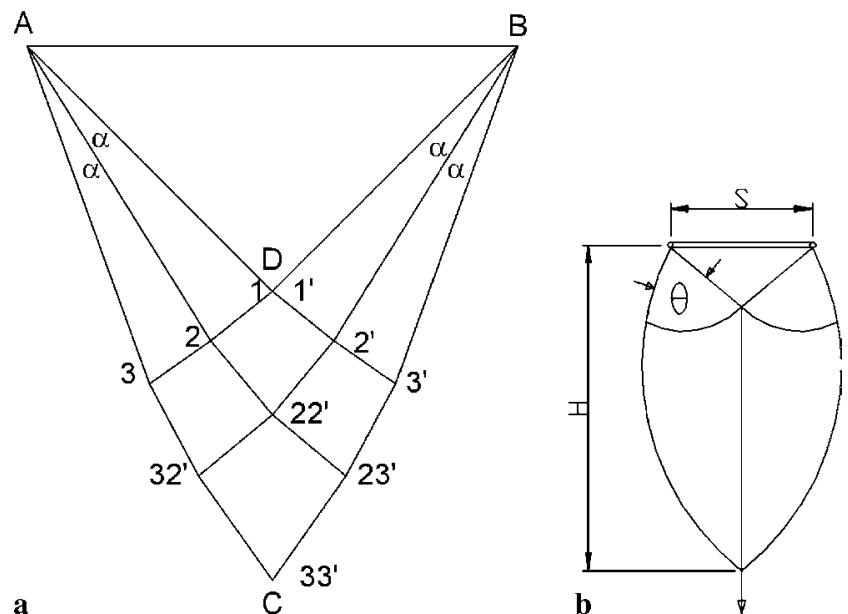

Fig. 9 a Construction of the slip lines, b Outer slip lines Abb. 9 a Konstruktion der Gleitlinien, b Äußere Gleitlinien 
or:

$\theta_{t} \approx 0.62 \ln (2 H / s)$

It thus is shown that Eq. A.11 is not an approximation but the true solution for the end point of the outer slip-lines.

Triangle ABD of Fig. 9 is a region of constant state, where the maximum shear lines, or characteristics, are everywhere at $45^{\circ}$ to the principal directions because of the uniform compression load on plane AB. Because now, the pole of the planes in the Mohr circle is at point $\sigma_{2}$ in Fig. 8, $\psi=\pi / 2$. This direction of the plane with the minor principle stress is also the direction of the highest principle compression stress.

From point D or $11^{\prime}$ in Fig. 9 and 10 to point 2 follows: $p_{s}-2 k \frac{\pi}{2}=p_{2^{\prime}}-2 k\left(\frac{\pi}{2}+\alpha\right) . \quad$ Thus: $\quad p_{2^{\prime}}=p_{s}-2 k \alpha$.

From point $2^{\prime}$ to $22^{\prime}$ it follows:

$p_{22^{\prime}}+2 k \frac{\pi}{2}=p_{2^{\prime}}+2 k\left(\frac{\pi}{2}-\alpha\right)$.

Thus: $p_{22^{\prime}}=p_{2^{\prime}}-2 k \alpha=p_{s}-4 k \alpha$ and: $p_{s}=p_{0}+4 k \alpha$.

The same relation follows for point $33^{\prime}$, when the angle between line $\mathrm{BD}$, and $\mathrm{BC}$ (at point B) is $2 \alpha: p_{s}=p_{0}+4 k(2 \alpha)$. Thus in general it is:

$p_{s}=p_{0}+4 k \theta$.

Inserting Eq. A.11 and with $p_{s}=\left(\sigma_{s}+\sigma_{s}-2 k\right) / 2=\sigma_{s}-k$ and $p_{0}=\sigma_{0}-k$, this is:

$\sigma_{s}=\sigma_{0}+2.48 \mathrm{k} \ln (2 \mathrm{H} / \mathrm{s})$

and because $\sigma_{s} s=\sigma_{0} L$ (see Fig. 11) it follows: $\sigma_{s}(1-$ $s / L)=2.48 k \ln (2 \mathrm{H} / \mathrm{s})$. Further elastic spreading will be at an angle of $45^{\circ}$, thus for initial (small) flow, $L \approx 2 H+s$, or:

$H \approx(L-s) / 2$ when $H>s$, thus: $L / s>3$.

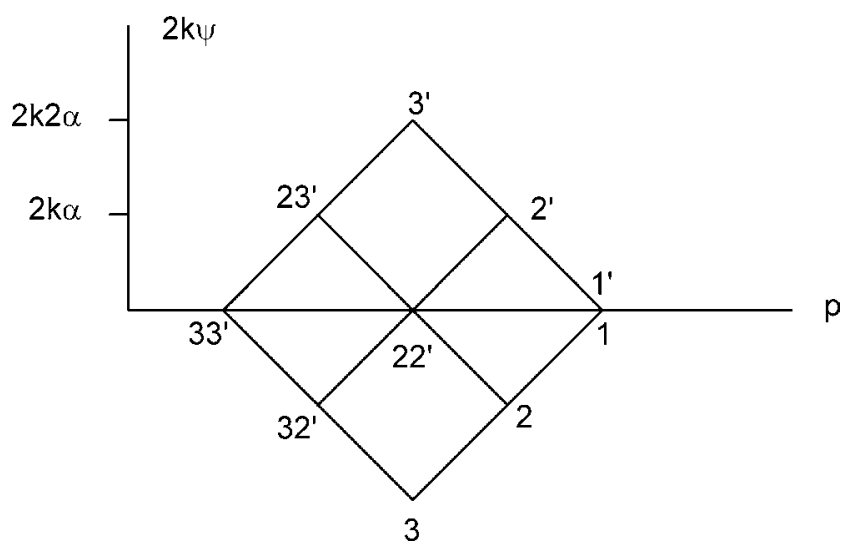

Fig. 10 Determination of $p$ and $\psi$ in the $p-2 k \psi$ plane Abb. 10 Bestimmung von $p$ und $\psi$ in der $p-2 k \psi$ Ebene

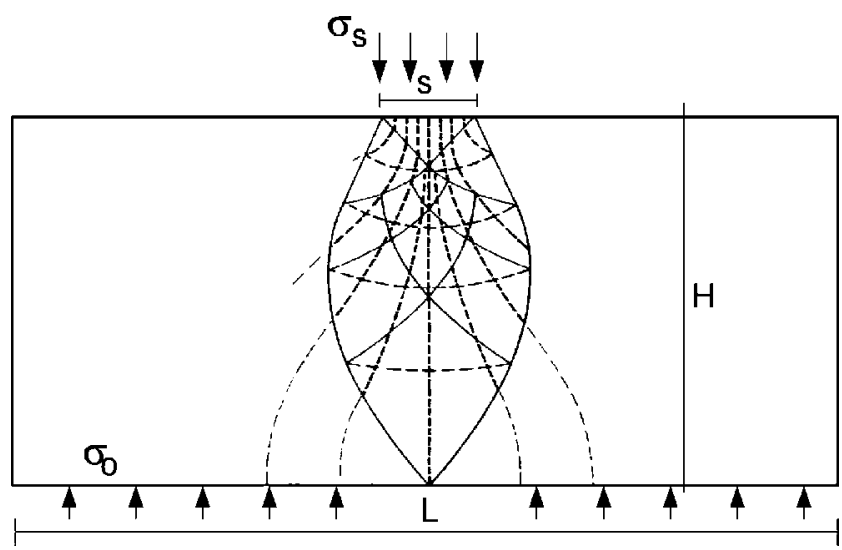

Fig. 11 "Slip-lines" determining the direction of the main stresses Abb.11 „Gleitlinien“, welche die Richtung der Hauptspannungen bestimmen

Substitution of the values for $\sigma_{0}$ and $H$ in Eq. A.13 gives:

$\sigma_{s}=2.48 k \ln \left(\frac{L}{s}-1\right) \frac{L / s}{L / s-1}$

and because from the power law approximation follows that $\ln \left(\frac{L}{s}-1\right) \frac{L / s}{L / s-1}$ is proportional to $\sqrt{L / s}$, (see Appendix B), Eq. A.14 becomes:

$\sigma_{s}=2.48 k C \sqrt{L / s}$,

where $C=(\sqrt{L / s} /(L / s-1)) \ln (L / s-1) \approx 0.78$.

Thus:

$\sigma_{s}=0.97 \cdot 2 k \sqrt{L / s} \approx 2 k \sqrt{L / s}$.

The value of $k$ follows from the compression test (cube test) with $\sigma_{1}=f_{c, 90}$ and $\sigma_{2}=0$ or: $k=f_{c, 90} / 2$. Thus Eq. A.16 becomes:

$f_{s}=c f_{c, 90 \sqrt{L / s}} \approx f_{c, 90} \sqrt{L / s}$.

The higher experimental value of $c$ given in Table 5 shows the lower boundary approach of the chosen method (the real slip-lines must give a higher value). Thus $c$ gives the possibility to adapt the model to test results.

A similar solution is possible for the rotational symmetrical case with a special value of the intermediate principal stress, leading to the extension of Eq. A.17 to the surfaces $A_{s}\left(\pi s^{2} / 4\right)$ and $A_{L}\left(\pi L^{2} / 4\right)$. Thus generalized to every surface form:

$f_{s}=c f_{c, 90} \sqrt{A_{L} / A_{s}}$.

It is shown in van der Put (2007) that the isotropic matrix of wood is determining the failure. Thus, the initial flow stress after elastic deformation at the bottom of the block where the outer slip lines cross each other in Fig. 11 is found by a spreading angle of $45^{\circ}$ of the load at plate "s" because then the mean spreading stress is equal to the maximal stress in 
this point according to the theory of elasticity. Due to hardening, the real maximal slope is 1.5 to 1 after huge plastic deformation where the maximal loading is reached.

\section{B Derivation of the power of the spreading equation}

The part of Eq. A.14 found in Appendix A: $(1.24(L / s)$ $\ln (L / s-1)) /(L / s-1)$, appears to follow the form of $\sqrt{L / s}$. This follows from the power law approximation of Eq. A.14. Any function can be approximated around a point $x_{0}$ by: $f(x)=f\left(x_{0}\right) \cdot\left(\frac{x}{x_{0}}\right)^{m}$, with: $m=\frac{f^{\prime}\left(x_{0}\right)}{f\left(x_{0}\right)}$, giving a power $m=0.5$. It thus is possible to split Eq. A.14 into:

$\sqrt{L / s}(1.24(\sqrt{L / s}) \ln (L / s-1)) /(L / s-1)=\sqrt{L / s} C$,

because the second part should be about constant.

The special value of 0.5 of the power can be explained as follows. In the following derivation, the strengths of the upper and bottom planes will be related to the strength of an intermediate plane " $m e$ ", having a strength according to the power law representation (analogous to Eq. A.18):

$\sigma_{m}=\sigma_{c}\left(\frac{L t}{m e}\right)^{n}$.

Thus from:

$\sigma_{m} m e=\sigma_{L} L t \rightarrow \sigma_{L}=\sigma_{m} \frac{m e}{L t}=\sigma_{c}\left(\frac{m e}{L t}\right)^{1-n}$

for the bottom plane. It also is for the upper plane: $\sigma_{s}=$ $\sigma_{m} \frac{m e}{t s}=\sigma_{c}\left(\frac{L t}{m e}\right)^{n} \frac{m e}{t s}=\sigma_{c}\left(\frac{L t}{m e}\right)^{n-1} \frac{L}{s}$.

With: $\quad m e=\alpha t s$

is: $\sigma_{L}=\sigma_{c}\left(\frac{m e}{L t}\right)^{1-n}=\sigma_{c} \alpha^{1-n}\left(\frac{s}{L}\right)^{1-n}$

and it is: $\sigma_{s}=\sigma_{c} \alpha^{1-n}\left(\frac{L}{s}\right)^{n}$.

In general, Eq. A. 1 is: $f(x)=f\left(x_{0}\right) \cdot\left(\frac{x}{x_{0}}\right)^{m}$, for $x=x_{0} \frac{s}{L}$, equal to: $\sigma_{L}=\sigma_{c} \alpha^{1-n}\left(\frac{s}{L}\right)^{1-n}$ and for $x=x_{0} \frac{L}{s}$, equal to: $\sigma_{s}=\sigma_{c} \alpha^{1-n}\left(\frac{L}{s}\right)^{n}$.

Because the exponent gives the slope of the curve and the curve should not be kinked at $x_{0}$, the exponents should be the same and: $m=1-n=n$, or $n=1 / 2$.
For $\alpha=1$, the intermediate plane is the determining upper plane

Open Access Dieser Artikel wird zu den Bedingungen der "Creative Commons Attribution Noncommercial License" zur Verfügung gestellt. Damit ist eine nichtkommerzielle Nutzung, Verbreitung und Vervielfältigung erlaubt, sofern die Autoren des Artikels und die genaue Quelle angegeben sind.

\section{References}

Augustin M, Ruli A, Brandner R, Schickhofer G (2006) Behaviour of glulam in compression perpendicular to grain in different strength grades and load configurations. CIB-W18/39-12-6, Florence

Ballerini M (1999) A new set of tests on beams loaded perpendicular to the grain by dowel joints, CIB-W18/32-7-2, Graz, Austria

Kollmann F (1984) Principles of wood science and technology, vol. I. Springer-Verlag, Berlin (reprint from 1951)

Korin U (1990) Compression perpendicular to grain. CIB-W18/23-61, Lisbon

Larsen HJ (1975) The design of timber beams. CIB-W18/5-10-1, Karlsruhe

van der Put TACM (1982) A general failure criterion for wood, Proc. IUFRO S5.02 paper 23, Boras, Sweden and the extension: The tensor-polynomial failure criterion for wood polymers. www.dwsf.nl/downloads.htm, Delft, 2005

Schwartz H (1969) Die Grenztragfähigkeit des Baugrundes bei Einwirkung vertikal gezogener Ankerplatten als zweidimensionales Bruchproblem. PhD dissert. University of Stuttgart

van der Put TACM (2007) A new fracture mechanics theory of orthotropic materials like wood. Eng Fract Mech 74:771-781

van der Put TACM (1988) Explanation of the embedding strength of particle board, EC-project MA1B-0058-NL, 1988 or Res. Report TU-Delft 25-88-63/09-HSC-6

See also the theoretical explanation of the strength of nailed particle board to wood connections in: Res. Reports 4-79-6/HSC-3; 4-803/HSC-4; and 4-81-7/HSC-5

van der Put TACM (1991) Discussion of the failure criterion for combined bending shear and compression. CIB-W18/24-6-1, Oxford

van der Put TACM, Leijten AJM (2000) Evaluation of perpendicular to the grain failure of beams by concentrated loads of joints. CIB-W18/33-7-7, NL

van der Put TACM (2006a) Derivation of the shear strength of continuous beams, www.dwsf.nl/downloads.htm, Delft and CIBW18/41. Date of access: May 2008

van der Put TACM (2006b) Determination of the bearing strength etc., DWSF-report www.dwsf.nl/downloads.htm. Date of access: May 2008 